\title{
TITULO DEL LIBRO: INSIDE JOB. HOW GOVERNMENT INSIDERS SUBVERT THE PUBLIC INTEREST
}

\author{
EDITORIAL: CAMBRIDGE UNIVERSITY PRESS
}

FECHA DE PUBLICACIÓN: 2017

AUTOR: MARK ZUPAN

\section{ANDRÉS ESCALANTE}

Quienes critican la corrupción en el Estado suelen enfocarse en el lado de la demanda, subrayando el papel que en ella desempeñan los gestores profesionales de intereses en nombre de sus clientes, cuyo propósito es, naturalmente, sesgar la política a su favor. Sin embargo, así como se necesitan dos para bailar un tango, la corrupción no es posible sin corruptores, como tampoco sin corrompidos. Es decir, la corrupción, para llevarse a cabo, precisa de quienes buscan favores, pero también de quienes los ofrecen. Los que están en la madeja - desde funcionarios públicos elegidos popularmente hasta burócratas de oficio y empleados públicos - pueden beneficiarse del Estado en formas varias, casi innumerables. Lógicamente, para ello se requiere de un orden institucional debidamente establecido. Este debe, como lo expuso Milton Friedman en alguna oportunidad, ser excluyente, de modo que beneficie a pocos, es decir, a quienes están adentro, a expensas de la mayoría, que, por supuesto, está afuera.

En Inside Job. How Government Insiders Subvert the Public Interest, Mark Zupan ahonda, por el lado de la oferta, en los intríngulis de esta alianza de hierro entre los funcionarios públicos, los grupos de interés y los burócratas de planta. La debida administración de la alianza permite para sus miembros la generación de ventajas financieras, visibilidad y estatus, poder político, consultorías y asesorías, por no decir empleo en las industrias de interés. Sin embargo, para muchos esta alianza perversa, así como su papel en la política, siguen siendo un misterio. Zupan pretende esclarecerlo en su libro.

Para ello, el autor establece un modelo económico de política en el que, en la oferta, encontramos a los miembros del Estado en calidad de "vendedores" de favores políticos; y en la demanda, nos topamos con las empresas, los sindicatos y los activistas. Zupan usa el modelo para examinar el efecto que la política motivada por funcionarios públicos ha tenido, tanto en casos históricos como en la actualidad. Como ejemplos de ello, analiza cómo el nepotismo y la protección de empleos oficiales arruinaron el Imperio otomano y, mucho antes, cómo los faraones y sus funcionarios destruyeron por la vía del derroche al Egipto mítico con la construcción de monumentos al ego y campañas militares. Luego, muestra la forma en que las mismas motivaciones y tendencias de entonces están poniendo en peligro a los gobiernos del presente.

La obra también enfatiza que, contrariamente a la opinión popular, no son solo las autocracias las que se hallan infestadas de corrupción. Abraham Lincoln quiso que el Estado fuese administrado por un gobierno del pueblo, por el pueblo y para el pueblo, y con ello es que asociamos a la democracia como sistema político. No obstante, ni las elecciones democráticas ni la rotación periódica de funcionarios elegidos son suficientes en sí para asegurar que el Estado funcione para la gente.

Por último, Zupan advierte en sus conclusiones que, si bien es arduo, sí es posible frenar, si no evitar, la captura del proceso político. Pero, para impedir que quienes forman la tiranía del statu quo subviertan el interés público, entre otras cosas, debemos, primero, entender quiénes son ellos y cuáles son sus acciones, cómo crece su influencia y por qué son difíciles de restringir, y, finalmente, cuándo estas acciones nos llevan al fracaso como nación.

Zupan dejó atrás su rol como decano de la Escuela de Negocios Simon, de la Universidad de Rochester, para escribir este libro en calidad de visiting fellow en el Instituto Cato en 2014, mientras asumía sus responsabilidades como presidente de la Universidad Alfred. El libro tiene 232 páginas y acaba de ser publicado en marzo de 2017 por el Instituto Cato y la Universidad de Cambridge.

Para Tyler Cowen, esta obra es "el mejor libro sobre cómo grupos de intereses especiales subvierten la calidad de la política pública". Estoy de acuerdo. 